\title{
Impact of a Discussion Series on Race on Medical Student Perceptions of Bias in Health Care
}

\author{
H. Reeve Bright, MD, MPH, MS | Keith Nokes, MD, MPH
}

PRiMER. 2019;3:29.

Published: 12/17/2019 | DOI: 10.22454/PRiMER.2019.142917

\section{Abstract}

Background and Objectives: Racial bias in health care is increasingly recognized as a factor in health inequities, yet there is limited research regarding medical school education around race and racism and its impact on medical students. The purpose of this study was to understand attitudes of medical students on race and racism in health care and to study the impact of participation in a voluntary structured program on race and racism.

Methods: First-year medical students had the opportunity to participate in a series of discussions (10 hours total) on race and racism. A 10-question survey addressing comfort, knowledge, and the adequacy of education on race and racism was sent to all first-year medical students ( $n=61 / 180$, response rate $34 \%)$, and was administered to series participants ( $n=23 / 25$, response rate $92 \%$ ) in a pre/post format.

Results: Participant and nonparticipant attitudes were similar at baseline, with the exception that participants were less likely to feel that the medical school curriculum provided adequate education on race and racism, and reported higher levels of knowledge around these issues. Following the discussion series, participants showed significant changes regarding knowledge and awareness, as well as comfort level discussing race and racism.

Conclusions: Participants were more likely than nonparticipants to think that the curriculum should include more discussion on race and racism. Postparticipation analysis demonstrated significant increases in comfort level, knowledge, and awareness in discussion of race and racism.

\section{Introduction}

Racial bias in medicine, including implicit, or unconscious bias, ${ }^{1}$ is increasingly recognized as a factor in health inequities affecting communication and the care offered to patients. ${ }^{2-5}$ Recent efforts have begun to engage health professionals in this issue, encouraging them to identify their own biases and identifying ways of combating health care disparities through allyship. ${ }^{6}$ However, information regarding medical school education around race and racism and its impact on students is limited. ${ }^{7}$ Discomfort with discussions of race outside of a biomedical context is common among medical students and health care professionals alike. ${ }^{8,9}$ Creating open discussions regarding race has shown benefits in health care work settings and in faculty development, ${ }^{10,11}$ but we have found no research addressing the impact of such forums in medical schools. Without adequate training, no improvement in cultural and racial sensitivity can be expected. ${ }^{6,12}$ A prerequisite for this is the creation of a safe environment in which students can acknowledge their biases, explore intentional behavior change, and increase confidence in addressing racial disparities. ${ }^{13}$ Students at one medical school implemented a program called the Race Dialogues Series (RDS), in order to have a forum for these discussions. 
The purpose of this study was to examine baseline perceptions of first-year medical students about race and health care as well as the impact of participation in the RDS. We hypothesized that participants and nonparticipants would vary significantly at baseline, with participants reporting greater comfort, knowledge, and awareness of racism, and that RDS participation would increase comfort and knowledge regarding these issues.

\section{Methods}

\section{Intervention}

In Spring 2016, 25 first-year medical students ("participants") at a single institution self-selected to participate in the RDS. First-year students who did not participate in the RDS were defined as "nonparticipants." This series of five 2-hour dialogues was based on a predefined curriculum and was lead by facilitators from YWCA Boston with experience in fostering safe environments for these difficult conversations. ${ }^{14}$ Participants verbally agreed to keep the content of these discussions confidential. Participants engaged in a variety of discussion topics including vocabulary around race, discrimination, and prejudice; self-identification, self-definition, stereotyping, and selfawareness; racism and bias in medicine; and strategies to address these issues.

\section{Survey (Figure 1)}

As a review of the literature did not identify a validated instrument measuring our targeted outcomes, we designed a 10-question Likert scale survey to assess attitudes toward inclusion of race and racism in the curriculum (questions 1 and 10), knowledge and awareness of racism and bias in health care and medical training (questions 2, 6, and 9), and confidence in talking about race and racism (questions $3,4,5$, and 7 ). Lower values on the 6-point scale indicated greater knowledge, comfort, or agreement with each question. Basic demographic information was obtained by self-report.

We administered the survey to RDS participants on paper in a pre/postformat, and concurrently to all first-year medical students via email. To avoid double counting, the email version included a question regarding RDS participation, and participants were reminded in person and via email not to respond to the online survey. The paper survey included the option to create a personalized code allowing for paired analysis. Participation was voluntary and anonymous. The Tufts University Institutional Review Board exempted the survey and the Office of Educational Affairs at Tufts University School of Medicine approved it.

\section{Data Analysis}

We compared the responses of nonparticipants to pretest responses of participants using an unpaired $t$ test. We also analyzed pre- and posttests of participant responses using an unpaired $t$ test. Sixteen of the 25 participants created individualized codes and were included in a paired pre/post $t$-test analysis. We performed data analysis with SPSS v20 (SPSS Statistical Software, Armonk, NY: IBM, Inc).

\section{Results}

Twenty-three (92\%) of the RDS participants took the pre/posttest survey. Sixteen (70\%) of these participants created an individualized code allowing for paired $t$-test analysis. Sixty-one (34\%) of the 180 nonparticipants completed the online survey. General demographic information was collected by self-report (Table 1).

\section{Participants vs Nonparticipants (Table 2)}

Nonparticipants were more likely to identify as white ( $80.3 \%$ vs $39.1 \%)$, and as not Hispanic/Latino ( $95.1 \%$ vs 78.3\%). At baseline, participants were significantly more likely than noparticipants to feel that the medical school curriculum should provide more discussion on race and racism (Q1: 1.22 vs 2.07, $P<.01,95 \% \mathrm{Cl}-1.43,-0.27$; Q10: 1.13 vs $2.13, P<.01,95 \% \mathrm{Cl}-1.37,-0.63)$. Additionally, participants were significantly more likely to self-report an understanding of the impact of race on medical care and health outcomes (Q6: 1.83 vs $2.34, P<.01,95 \% \mathrm{Cl}-0.91$, $-0.31)$. 


\section{Unpaired Participant Pre/Post $t$ Test (Table 2)}

The unpaired $t$-test analysis of participants $(n=23)$ showed statistically significant changes in several domains. Participants reported increased knowledge and awareness of racial bias (Q2: 3.35 vs 2.30, $P=.03,95 \% \mathrm{Cl} 0.12,1.97$; Q6: $1.83 \vee 1.43, P=0.04,95 \% \mathrm{Cl} 0.02,0.76 ; \mathrm{Q} 9: 4.04 \vee 2.47, P<.01,95 \% \mathrm{Cl} 0.62,2.34)$, as well as an increased level of comfort talking about race and racism (Q7: 2.87 vs $2.13, P=.01,95 \% \mathrm{Cl} 0.24,1.24 ; \mathrm{Q} 8: 2.65$ vs $1.96, P=.01,95 \% \mathrm{Cl}$ $0.17,1.23)$.

\section{Paired Participant Pre/Post t-Test (Table 2)}

Paired pre/posttest analysis demonstrated significant changes in responses to the same questions as the unpaired analysis (Q2: 3.31 vs $2.00, P<.01 ; \mathrm{Q} 6: 1.88$ v $1.44, P=0.03 ; \mathrm{Q} 7: 3.00$ vs $2.25, P<.01 ; \mathrm{Q} 8: 2.81$ vs $2.00 P=.01 ; \mathrm{Q}$ : 4.13 vs $2.31, P<.01)$, while additionally showing a significant increase in self-reported comfort talking about race (Q4: 2.44 vs $1.88, P<.01)$. We did not perform within-group variance due to small sample sizes in certain categories.

\section{Discussion}

Despite growing recognition of the role of race and racism in health inequities, there is little information regarding interventions to address these issues during medical training. In this study, participants in a structured discussion series reported increased awareness of race and racism, specifically demonstrating increased recognition of others' experiences of racism and greater understanding of the role of race in medical care and health outcomes. Participants also reported increased comfort talking about race and racism with other health professionals, with patients, and with people from different racial backgrounds. Notably, these changes occurred despite the fact that participants were a self-selected group with a higher initial knowledge of these concepts.

Study limitations include the small sample size and the short timeline of the intervention and postparticipation survey. RDS participants may have been affected by selection bias, as participation was voluntary, and participants may have been predisposed toward sensitivity and awareness on issues surrounding race and racism. Selection bias may also have minimized the baseline difference between participants and nonparticipants as the nonparticipating students who responded to the class-wide survey may be more attuned to issues surrounding racial bias in health care than nonresponders. Additionally, RDS occurred in the context of highly visible discussions of race and racism such as the Black Lives Matter movement. This is a potential confounder, though the limited study time frame may make this less likely.

A separate concern is program generalizability. Organizers of the RDS benefited from the availability of a community partner with trained facilitators, but the program as designed requires student commitment, openness to selfreflection and discussing racism, and structured groups. Providing resources to support this program for all students would be difficult, and requiring participation could jeopardize the underlying ethos of safe and open discussion, potentially affecting total program impact.

Finally, it is difficult to know the true impact of small but significant changes on a Likert scale, but addressing these issues is an ongoing process and the Race Dialogues Series offers one potential model to create change. Potential future steps include expanding this curriculum to more students, beginning similar discussions at other institutions, and evaluating for future program sustainability. It is imperative that we as medical educators move the discussion on race and racism forward if we are to address their impact in our practice of medicine and in patient outcomes and health inequities.

\section{Tables and Figures}


Figure 1: Race Dialogues Survey

\begin{tabular}{|c|c|c|c|c|c|c|}
\hline & $\begin{array}{l}\text { Strongly } \\
\text { Agree }\end{array}$ & Agree & $\begin{array}{l}\text { Somewhat } \\
\text { Agree }\end{array}$ & $\begin{array}{l}\text { Somewhat } \\
\text { Disagree }\end{array}$ & Disagree & $\begin{array}{l}\text { Strongly } \\
\text { Disagree }\end{array}$ \\
\hline \multicolumn{7}{|l|}{$\begin{array}{l}\text { Q1. I believe that the medical school } \\
\text { should integrate discussion of ethnicity } \\
\text { and race throughout the curriculum. }\end{array}$} \\
\hline \multicolumn{7}{|l|}{$\begin{array}{l}\text { Q2. I, or individuals I know, have } \\
\text { experienced racism and/or racial } \\
\text { microaggressions }{ }^{1} \text { at the medical school. }\end{array}$} \\
\hline \multicolumn{7}{|l|}{$\begin{array}{l}\text { Q3. I am confident interacting with } \\
\text { people who come from a different racial } \\
\text { or ethnic background than my own. }\end{array}$} \\
\hline \multicolumn{7}{|l|}{$\begin{array}{l}\text { Q4. I feel comfortable talking about } \\
\text { race with people from a different racial } \\
\text { background than my own. }\end{array}$} \\
\hline \multicolumn{7}{|l|}{$\begin{array}{l}\text { Q5. I feel comfortable talking about } \\
\text { racism. }\end{array}$} \\
\hline \multicolumn{7}{|l|}{$\begin{array}{l}\text { Q6. I understand how race impacts } \\
\text { medical care and health outcomes. }\end{array}$} \\
\hline \multicolumn{7}{|l|}{$\begin{array}{l}\text { Q7. I would feel comfortable talking } \\
\text { about race with my patients. }\end{array}$} \\
\hline \multicolumn{7}{|l|}{$\begin{array}{l}\text { Q8. I would feel comfortable talking } \\
\text { about race and racism with other health } \\
\text { care professionals. }\end{array}$} \\
\hline \multicolumn{7}{|l|}{$\begin{array}{l}\text { Q9. I, or individuals I know, have } \\
\text { experienced institutional racism }{ }^{2} \text { at the } \\
\text { medical school. }\end{array}$} \\
\hline $\begin{array}{l}\text { Q10. I believe that the medical school } \\
\text { should provide a forum to talk about } \\
\text { race. }\end{array}$ & & & & & & \\
\hline
\end{tabular}

1. Microaggressions are "brief and commonplace daily verbal, behavioral, or environmental indignities, whether intentional or unintentional, that communicate hostile, derogatory, or negative racial slights and insults towards people of color."

Source: Sue DW, Capodilupo C, Torino G, Bucceri J, Holder A, Nadal K, Equin M. Racial Microaggressions in Everyday Life: Implications for Clinical Practice. The American Psychologist. 2007; 62(4):271-286.

2. Institutional racism is a subtle pattern of racism by social institutions (such as government organizations, schools, banks, and courts) that result in discrimination, either deliberately or indirectly, against certain groups of people based on their race. It "reflects the cultural assumptions of the dominant group, so that the practices of that group are seen as the norm to which other cultural practices should conform."

Source: Gay K. Bigotry and Intolerance: The Ultimate Teen Guide. 1st ed. Ch1, p 7. Lanham, MD: Scarecrow Press; 2013. 
Table 1: Self-Reported Demographics of Race Dialogue Series Participants and Nonparticipants

\begin{tabular}{|c|c|c|c|}
\hline Characteristic & Nonparticipant, n (\%) & Participant, n (\%) & Total, n (\%) \\
\hline \multicolumn{4}{|l|}{ Gender } \\
\hline Male & $26(42.6)$ & $5(21.7)$ & $31(36.9)$ \\
\hline Female & $35(57.4)$ & 18 (78.3) & 53 (63.1) \\
\hline \multicolumn{4}{|l|}{ Ethnicity } \\
\hline Hispanic/Latino & $3(4.9)$ & $5(21.7)$ & $8(9.5)$ \\
\hline Not Hispanic/Latino & $58(95.1)$ & $18(78.3)$ & $76(90.5)$ \\
\hline \multicolumn{4}{|l|}{ Race } \\
\hline White & $49(80.3)$ & $9(39.1)$ & $58(69.0)$ \\
\hline Black, African American & $2(3.3)$ & $4(17.4)$ & $6(7.1)$ \\
\hline Middle Eastern & $0(0.0)$ & $1(4.3)$ & $1(1.2)$ \\
\hline South Asian & $2(3.3)$ & $2(8.7)$ & $4(4.8)$ \\
\hline Other Asian & $4(6.6)$ & $6(26.1)$ & $10(11.9)$ \\
\hline Other & $3(4.9)$ & $1(4.3)$ & $4(4.8)$ \\
\hline No answer & $1(1.6)$ & $0(0.0)$ & $1(1.2)$ \\
\hline Total & 61 & 23 & 84 \\
\hline
\end{tabular}

Table 2: Results of the Race Dialogue Series Survey by Question

\begin{tabular}{|c|c|c|c|c|c|c|}
\hline & \multicolumn{2}{|c|}{$\begin{array}{l}\text { Participant }(n=23) \text { v. } \\
\text { Nonparticipant }(n=61)\end{array}$} & \multicolumn{2}{|c|}{$\begin{array}{l}\text { Participant Unpaired } \\
\text { Pre/Postsurvey }(n=23) \\
\end{array}$} & \multicolumn{2}{|c|}{$\begin{array}{l}\text { Participant Paired Prel } \\
\text { Postsurvey }(n=16)\end{array}$} \\
\hline & P Value & $95 \% \mathrm{Cl}$ & PValue & $95 \% \mathrm{Cl}$ & $t(d f)$ & $\begin{array}{l}\text { Sig. } \\
\text { (2-talled) }\end{array}$ \\
\hline Q1. Integrate discussion & $<.01^{*}$ & $-1.43,-0.27$ & 1.00 & $-0.44,0.44$ & $0.00(15)$ & 1.00 \\
\hline Q2. Microaggression & .08 & $-1.52,0.09$ & $.03^{*}$ & $0.12,1.97$ & $3.63(15)$ & $<.01^{*}$ \\
\hline Q3. Confident interacting & .96 & $-0.41,0.39$ & .08 & $-0.04,0.65$ & $1.78(15)$ & .10 \\
\hline Q4. Talking about race & .20 & $-1.06,0.23$ & .25 & $-0.23,0.83$ & $3.09(15)$ & $<.01^{*}$ \\
\hline Q5. Talking about racism & .18 & $-1.01,0.19$ & .07 & $-0.04,0.91$ & $1.70(15)$ & .11 \\
\hline Q6. Race impacts medical care & $.01^{*}$ & $-0.91,-0.31$ & $.04^{*}$ & $0.02,0.76$ & $2.41(15)$ & $.03^{*}$ \\
\hline Q7. Race and patients & .75 & $-0.70,0.51$ & $.01^{*}$ & $0.24,1.24$ & $3.22(15)$ & $<.01^{*}$ \\
\hline $\begin{array}{l}\text { Q8. Race and other health care } \\
\text { professionals }\end{array}$ & .47 & $-0.36,0.78$ & $.01^{*}$ & $0.17,1.23$ & $2.78(15)$ & $.01^{*}$ \\
\hline Q9. Institutional racism & .30 & $-1.07,0.34$ & $<.01^{*}$ & $0.62,2.34$ & $4.53(15)$ & $<.01^{*}$ \\
\hline Q10. Forum to talk about race & $<.01^{*}$ & $-1.37,-0.63$ & .31 & $-0.08,0.26$ & $1.46(15)$ & .16 \\
\hline
\end{tabular}

* Statistically significant result

\section{Acknowledgments}

The authors acknowledge the Sam W. Ho Health Justice Scholars Program (formerly Tufts Student Service Scholars), YWCA Boston, and Tufts University School of Medicine.

Financial Support: This study received financial support from the Jonathan M. Tisch College of Civic Life, Tisch Fund for Civic Engagement; and from theTufts University School of Medicine, Department of Family Medicine.

Presentations: This study was presented as a Completed Peer Paper at the Society of Teachers of Family Medicine 


\section{Corresponding Author}

H. Reeve Bright, MD, MPH, MS

Montefiore Medical Center, Department of Family and Social Medicine, 3544 Jerome Ave, Bronx, NY 10467. 484-643-2816. Fax: 718-515-5416.

hbright@montefiore.org

\section{Author Affiliations}

H. Reeve Bright, MD, MPH, MS - Montefiore Medical Center, Department of Family and Social Medicine, Bronx, NY Keith Nokes, MD, MPH - Tufts University School of Medicine, Department of Family Medicine, Boston, MA

\section{References}

1. Institute of Medicine Committee on Understanding and Eliminating Racial and Ethnic Disparities in Health Care. In: Institute of Medicine (US) Committee on Understanding and Eliminating Racial and Ethnic Disparities in Health Care; Smedley BD, Stith AY, Nelson AR, editors. Washington, DC: National Academies Press; 2003.

2. Nelson SC, Prasad S, Hackman HW. Training providers on issues of race and racism improve health care equity. Pediatr Blood Cancer. 2015;62(5):915-917. https://doi.org/10.1002/pbc. 25448

3. Williams DR, Mohammed SA. Discrimination and racial disparities in health: evidence and needed research. J Behav Med. 2009;32(1):20-47. https://doi.org/10.1007/s10865-008-9185-0

4. Blair IV, Steiner JF, Havranek EP. Unconscious (implicit) bias and health disparities: where do we go from here? Perm J. 2011;15(2):71-78.

5. Sabin JA, Greenwald AG. The influence of implicit bias on treatment recommendations for 4 common pediatric conditions: pain, urinary tract infection, attention deficit hyperactivity disorder, and asthma. Am J Public Health. 2012;102(5):988-995. https://doi.org/10.2105/AJPH.2011.300621

6. Wu D, Saint-Hilaire L, Pineda A, et al. The efficacy of an antioppression curriculum for health professionals. Fam Med. 2019;51(1):22-30. https://doi.org/10.22454/FamMed.2018.227415

7. Zhang AL. Race in medical education. Brown Medicine Magazine. Winter 2017. https://medicine.at.brown.edu /article/race-in-medical-education/. Accessed December 4, 2019.

8. Roberts JH, Sanders T, Wass V. Students' perceptions of race, ethnicity and culture at two UK medical schools: a qualitative study. Med Educ. 2008;42(1):45-52. https://doi.org/10.1097 /00001888-194101000-00009

9. Dennis SN, Gold RS, Wen FK. Learner reactions to activities exploring racism as a social determinant of health. Fam Med. 2019;51(1):41-47. https://doi.org/10.22454/FamMed.2019.704337

10. Nunez-Smith M, Curry LA, Berg D, Krumholz HM, Bradley EH. Healthcare workplace conversations on race and the perspectives of physicians of African descent. J Gen Intern Med. 2008;23(9):1471-1476. https://doi.org /10.1007/s11606-008-0709-7

11. White-Davis T, Edgoose J, Brown Speights JS, et al. Addressing racism in medical education: an interactive training module. Fam Med. 2018;50(5):364-368. https://doi.org/10.22454/FamMed.2018.875510 .

12. Lee $M$, Coulehan JL. Medical students' perceptions of racial diversity and gender equality. Med Educ. 2006;40(7):691-696. https://doi.org/10.1111/j.1365-2929.2006.02516.x

13. Chapman EN, Kaatz A, Carnes M. Physicians and implicit bias: how doctors may unwittingly perpetuate health care disparities. J Gen Intern Med. 2013;28(11):1504-1510. https://doi.org/10.1007/s11606-013-2441-1

14. YWCA. YW Boston Presents: A Taste of the Dialogues. 2015. http://www.slideshare.net/ywboston/yw-bostonpresents-a-taste-of-the-dialogues. Accessed December 4, 2019. 